\title{
A IMPORTANCIA DO DESENVOLVIMENTO DA COMPETÊNCIA EM INFORMAÇÃO NO CONTEXTO DE CLUBES DE FUTEBOL
}

\author{
Carlos Francisco Bitencourt Jorge* \\ Marta Lígia Pomim Valentim ${ }^{* *}$
}

A informação é um dos componentes implícitos em distintos processos organizacionais, assim, é necessário que os sujeitos organizacionais sejam dotados de competências que proporcione o melhor aproveitamento de dados e informações. Ao observar o ambiente em que os clubes de futebol estão inseridos é possível notar o uso de dados e informações a todo instante e, em grande parte do tempo, sendo utilizada como recurso estratégico. Nessa perspectiva, analisa-se a percepção, acesso, compartilhamento e uso de dados e informação alinhados à competência em informação no Marília Atlético Clube, da Cidade de Marília, interior do Estado de São Paulo. Para tanto, realizou-se uma pesquisa de natureza qualitativa, aplicando-se o método de observação direta para a coleta e análise dos dados. A partir da análise foi possível perceber de que maneira os sujeitos organizacionais usam a informação, bem como evidenciou-se a importância do desenvolvimento da competência em informação, de modo que possam exercer suas funções, responsabilidades e tarefas desempenhadas no Clube. Evidenciou-se também distintas necessidades informacionais quanto ao uso de dados e informações, confirmando que o desenvolvimento da competência em informação no contexto dos clubes de futebol é essencial, afinal, todos os envolvidos no Clube possuem necessidades em informação e, portanto, necessitam desenvolver competências voltadas ao melhor uso das informações.

Palavras-Chave: Competência em Informação. Gestão da Informação. Informação Esportiva. Ambientes Esportivos. Clubes de Futebol.

\footnotetext{
* Mestre em Ciência da Informação pela Universidade Estadual Paulista Júlio de Mesquita Filho, Brasil. Doutorando em Ciência da Informação com enfoque em Gestão do Conhecimento e Inteligência Competitiva em Organizações Complexas pela Universidade Estadual Paulista Júlio de Mesquita Filho, Brasil. E-mail: bitencourt@gmail.com.

* Doutora em Ciências da Comunicação pela Universidade de São Paulo, Brasil. Professora Adjunta da Universidade Estadual Paulista Júlio de Mesquita Filho, Brasil. Docente permanente no Programa de PósGraduação em Ciência da Informação da Universidade Estadual Paulista Júlio de Mesquita Filho, Brasil.

E-mail: valentim@valentim.pro.br.
}

\section{INTRODUÇÃO}

A

o realizarem processos, atividades e tarefas os sujeitos organizacionais interagem a todo momento com dados, informações e conhecimentos, ou seja, esses elementos são inerentes seja de maneira direta, seja de indireta. Choo (2003) destaca essa interrelação e ressalta a falta de percepção por parte dos gestores, no que tange a importância desses elementos para as organizações:

\begin{abstract}
A informação é um componente intrínseco de quase tudo que uma organização faz. Sem uma compreensão dos processos organizacionais pelos quais a informação se transforma em percepção, conhecimento e ação, as empresas não são capazes de perceber a importância de suas fontes e tecnologias de informação (CHOO, 2003, p.27).
\end{abstract}

No ambiente organizacional, bem como no mercado em que estão inseridas, a 
informação pode fazer a diferença em vários aspectos, sendo muitas vezes não percebida por quem realiza as ações organizacionais. A informação é essencial para o estabelecimento de diferenciais competitivos, para o fortalecimento da cultura organizacional, para a geração de inovação, entre outros. Segundo Moraes e Fadel (2007, p.103), as informações “[...] apoiam o processo decisório, exercem influencias sobre o comportamento das pessoas e passa a ser um vetor importantíssimo, pois podem multiplicar a sinergia dos esforços ou anular o resultado obtido pelo conjunto".

Nessa perspectiva, a informação deve ser considerada como um componente estratégico e, por essa razão, sua gestão deve ser realizada de maneira plena. Os ambientes esportivos são locais com grande concentração de informações, em que são geradas e utilizadas a todo instante e em diferentes contextos, mesmo sem haver a percepção dos processos informacionais por parte dos sujeitos organizacionais.

Em um clube de futebol essa situação não é diferente, informações são geradas e utilizadas a todo momento. Compreender a percepção, compartilhamento e uso da informação nesse contexto torna-se importante para reconhecer os perfis, comportamentos e necessidades dos sujeitos organizacionais, de modo a estabelecer estratégias e ações voltadas ao desenvolvimento de competências em informação (CoInfo) nos sujeitos organizacionais.

\section{A INFORMAÇÃO E SUA RELAÇÃO COM AMBIENTE ESPORTIVO}

Conforme mencionado anteriormente, a informação é considerada um componente intrínseco de atividades e fazeres organizacionais. Todo tipo de organização se relaciona diretamente com dados, informações e conhecimento, entretanto, os sujeitos organizacionais, geralmente, não possuem a percepção da real importância desses elementos para seu próprio desempenho.

No universo organizacional, observa-se diferentes tipos de informações, cuja tipologia é variável para cada tipo de organização. Valentim (2006, p.12-14) destaca distintos ambientes e tipos informacionais, entre eles: informação estratégica, informação financeira, informação comercial, informação estatística, informação tecnológica, informação jurídica, entre outras.

As organizações esportivas, mais especificamente os clubes de futebol possuem as informações supracitadas, mas tendo como background o ambiente esportivo. Jorge e Valentim (2015, p.187) definem o conceito de informação esportiva destacando sua relação com ambiente, bem como chamam a atenção para as múltiplas visões de uma mesma informação no ambiente esportivo:

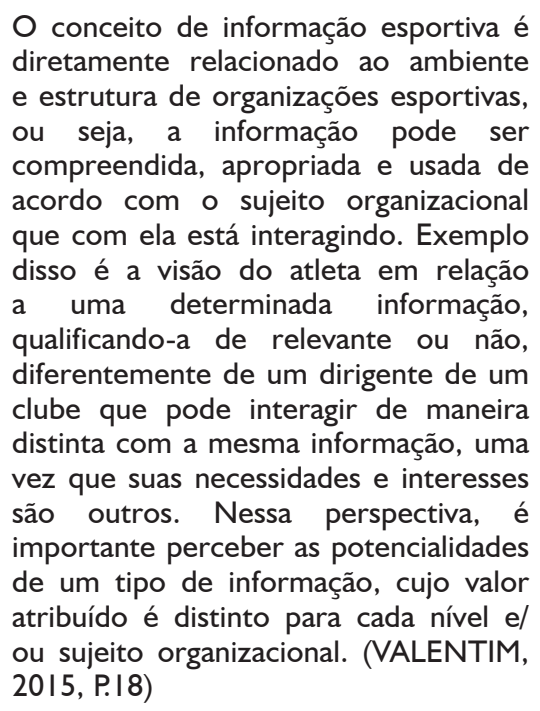

Dessa maneira, evidencia-se que a dinâmica do ambiente influencia e impacta os processos organizacionais, bem como as informações que trafegam no ambiente interno e externo das organizações esportivas.

Jorge e Valentim (2015) explicam que, de acordo com as necessidades/demandas dos sujeitos organizacionais, as informações de distintas fontes e ambientes podem se interrelacionar, transformando-se em novos dados e informações, fator que possibilita a geração de conhecimento (Quadro 1). Nessa perspectiva, evidencia-se a importância das informações, bem como sua aplicação com o intuito de desenvolver diferenciais competitivos e estratégias de ação de curto, médio e longo prazo. 
Quadro 1: Tipologia, tipo de informação, fonte e ambiente.

\begin{tabular}{|l|l|l|c|}
\hline Tipologia & Informação & \multicolumn{1}{c|}{ Fonte } & Ambiente \\
\hline Formal & Médica & Área Técnica & Interno \\
\hline Formal & Física & Área Técnica & Interno \\
\hline Formal & Atletas (treinos e competições) & Área Técnica & Interno \\
\hline Formal & Financeira & Área Administrativa & Interno \\
\hline Formal & $\begin{array}{l}\text { Administrativa (contratos de atletas, } \\
\text { patrocínio) }\end{array}$ & Área Administrativa & Interno \\
\hline Formal & Marketing & Área Administrativa & Interno \\
\hline Formal & Sócios & Área Administrativa & Interno \\
\hline Formal & Atletas observados & $\begin{array}{l}\text { Internet, TV, empresários, } \\
\text { entre outros. }\end{array}$ & Externo \\
\hline Informal & Torcedores & $\begin{array}{l}\text { Internet (redes sociais), } \\
\text { TV, institutos de } \\
\text { pesquisa, entre outros. }\end{array}$ & Externo \\
\hline Informal & Partida & Área Técnica & Externo \\
\hline Informal & $\begin{array}{l}\text { Mercado de investimentos (Especulação de } \\
\text { atletas e patrocínio) }\end{array}$ & $\begin{array}{l}\text { Empresários, jornais, } \\
\text { internet entre outras } \\
\text { fontes. }\end{array}$ & Externo \\
\hline Informal & Partida (Jogadas para análise dos árbitros) & Partida em andamento & Externo \\
\hline Informal & $\begin{array}{l}\text { Informações não mapeadas (Em processo de } \\
\text { transformação) }\end{array}$ & Várias (Indefinidas) & $\begin{array}{c}\text { Externo/ } \\
\text { Interno }\end{array}$ \\
\hline
\end{tabular}

Fonte: Jorge e Valentim (2015, p.187)

Davenport e Harris (2007) mencionam o uso da informação para obter vantagem competitiva em esportes como, por exemplo, no beisebol, basquete, futebol americano, entre outros. No contexto do ambiente técnico, a estatística é utilizada com frequência em esportes como basquete e beisebol gerando dados e informações que, em um segundo momento serão objeto de análise, visando gerar inteligência, buscando a melhoria contínua do esporte. Esse tipo de análise é realizado por indivíduos dos clubes, como é o caso do técnico do St. Louis Cardinals, Tony La Russa (cujo time venceu o World Series em 2006), "[...] um dos melhores treinadores de beisebol, combina de forma brilhante a inteligência analítica e a intuição para decidir quando contratar uma personalidade contagiante para alavancar o moral da equipe" (DAVENPORT; HARRIS, 2007, p.22).

Os clubes de futebol americano possuem a percepção da importância da aplicação da informação para obter vantagem competitiva. Essa percepção alinhada às estratégias organizacionais fazem de o futebol americano ser considerado um negócio e, consequentemente, torna-o um dos esportes mais lucrativos do mundo.

Davenport e Harris (2007) citam o New England Patriots, tradicional Clube de Futebol Americano, que utiliza a informação com diferentes objetivos organizacionais como, por exemplo, o contexto mercadológico cujas análises são centradas nos torcedores, assim,

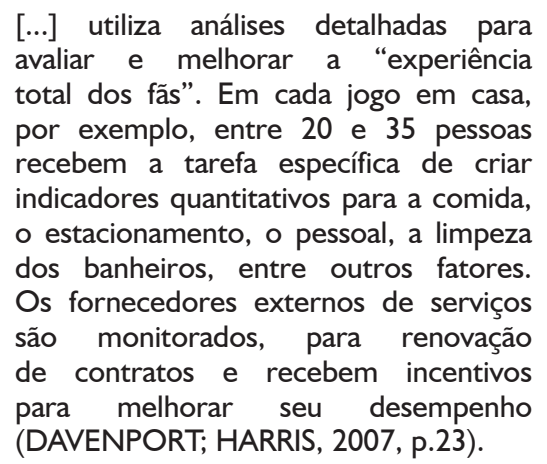

O New England Patriots realiza seu planejamento estratégico buscando atender as necessidades da área técnica alinhando-o às suas disponibilidades financeiras. 
O New England Patriots, por exemplo, tem demonstrado um desempenho particularmente bem-sucedido, com a vitória recente de três Super Bowls' em quatro anos. O time faz uso extensivo de dados e modelos analíticos, tanto em campo quanto fora dele. Profundas análises ajudaram o time a selecionar seus jogadores e ainda permanecer abaixo do teto salarial (no ano passado, a média salarial do time ficou no vigésimo quarto lugar na National Football League $^{2}$ ). $O$ time seleciona jogadores sem utilizar os serviços de olheiros empregados por outros times e classifica as seleções potenciais com base em fatores não tradicionais, como inteligência e disposição de usar o ego pessoal em benefício da equipe (DAVENPORT; HARRIS, 2007, p.22-23). comissão técnica é capaz de projetar situações e antever a estratégia dos adversários. Os membros da comissão técnica

[...] fazem a utilização extensiva da inteligência analítica para decisões em campo. Eles empregam estatísticas para decidir se tentam fazer um ou dois pontos depois de um touchdown ou se desafiam a decisão do juiz, por exemplo. Tanto seus técnicos quanto os jogadores são reconhecidos por seu extensivo estudo de filmagem de jogos e estatística, e o treinador chefe, Bill Belichick, é famoso por ler compenetradamente artigos de economistas acadêmicos sobre probabilidades estatísticas de resultado do futebol americano (DAVENPORT; HARRIS, 2007, p.23). subsidiadas por informações, com isso a

Figura 1: Informação formal e informal e a geração de nova informação/conhecimento.

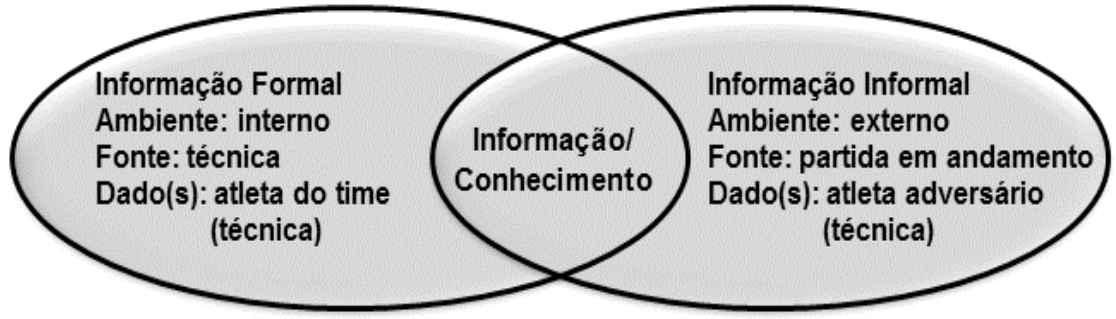

Fonte: Jorge e Valentim (2015, p.189).

Considerando a informação como elemento estratégico para o desenvolvimento das atividades organizacionais, no ambiente esportivo possuem um valor inestimável

I Super Bowl é um jogo do campeonato da National Football League (NFL) estadunidense que decide o campeão da temporada do ano anterior. Disputada desde 1967, a partir da junção das duas principais ligas do desporto no país (NFC e AFC), é o maior evento desportivo e a maior audiência televisiva do país, assistido anualmente por milhões de pessoas nos Estados Unidos e em todo o mundo. É também um evento que apresenta a publicidade mais cara da televisão, pois patrocinadores desembolsam pequenas fortunas para exibirem suas propagandas no intervalo. Disponível em: <http://pt.wikipedia.org/wiki/Super_Bowl > Acesso em: 22 jul. 2012

2 A National Football League (NFL) é a maior liga de futebol americano do mundo, com trinta e dois times nos Estados Unidos. Em termos de renda e número de fãs, a NFL é a maior liga de esportes na América do Norte. O valor médio dos clubes avaliado em 2008 é de I,04 bilhão de dólares, sendo o mais valioso o Dallas Cowboys, que chega a valer I,6I 2 bilhão de dólares. A divisão mais valiosa da NFL é a NFC Leste, formada por Cowboys, Washington Redskins, New York Giants e Philadelphia Eagles, todos valendo mais de um bilhão de dólares. Disponível em: $<$ http://pt.wikipedia.org/wiki/National_Football_League>. Acesso em: 22 jul. 2012.
(Figura 1). Observa-se que, a inter-relação de informações de diferentes tipologias, ambientes, fontes e dados são capazes de subsidiar novas informações e conhecimentos que, por sua vez, podem ser utilizados de maneira estratégica pelos sujeitos organizacionais, proporcionando diferenciais competitivos em diferentes contextos.

\section{COMPETÊNCIA EM INFORMAÇÃO COMO ATIVIDADE ESTRATÉGICA PARA A GESTÃO DA INFORMAÇÃO E DO CONHECIMENTO}

A implementação de modelos de Gestão da Informação (GI) e Gestão do Conhecimento (GC) neces- 
sitam ter como base estruturante o desenvolvimento de programas e/ou atividades voltadas ao desenvolvimento de Competências em Informação (CoInfo), de maneira a propiciar as condições necessárias para que os sujeitos organizacionais possam gerar informações e conhecimentos necessários à organização.
As atividades realizadas nos processos de GI e GC, apesar de haver uma inter-relação e dependência entre elas, são distintas. Valentim (2002) estabeleceu as principais atividades de GI e GC (Quadro 2).

Quadro 2: Atividades de gestão da informação e gestão do conhecimento.

\begin{tabular}{|c|c|}
\hline Gestão da Informação & Gestão do Conhecimento \\
\hline Foco: Negócio d & Foco: Capital Intelectual da Organização \\
\hline $\begin{array}{l}\text { - Prospecção, seleção e obtenção da } \\
\text { informação; } \\
\text { - Mapeamento e reconhecimento dos fluxos } \\
\text { formais de informação; } \\
\text { - Tratamento, análise e armazenamento } \\
\text { da informação utilizando tecnologias de } \\
\text { informação; } \\
\text { - Disseminação e mediação da informação ao } \\
\text { público interessado; } \\
\text { - Criação e disponibilização de produtos e } \\
\text { serviços de informação. }\end{array}$ & $\begin{array}{l}\text { Desenvolvimento da cultura organizacional } \\
\text { voltada ao conhecimento; } \\
\text { - Mapeamento e reconhecimento dos fluxos } \\
\text { informais de informação; } \\
\text { - Tratamento, análise e agregação de valor } \\
\text { às informações utilizando tecnologias de } \\
\text { informação; } \\
\text { - Transferência do conhecimento ou } \\
\text { socialização do conhecimento no ambiente } \\
\text { organizacional; } \\
\text { - Criação e disponibilização de sistemas } \\
\text { de informação empresariais de diferentes } \\
\text { naturezas. }\end{array}$ \\
\hline $\begin{array}{l}\text { Trabalha essencialmente com os fluxos formais } \\
\text { de informação }\end{array}$ & $\begin{array}{l}\text { Trabalha essencialmente com os fluxos } \\
\text { informais de informação }\end{array}$ \\
\hline
\end{tabular}

Fonte: Adaptado de Valentim (2002, p.3).

A GI trabalha com as informações que tramitam nos fluxos formais, ou seja, informações registradas em diferentes tipos de suporte, por outro lado a GC trabalha com os fluxos informais, isto é, refere-se ao conhecimento tácito dos sujeitos organizacionais que não foram explicitados, mas que estão presentes em ações, observações e conversas informais. Tanto a GI quanto a GC enfocam o sujeito organizacional, uma vez que nos dois modelos de gestão os indivíduos são produtores e consumidores de informação e conhecimento.

Valentim, Jorge e Ceretta-Soria (2014, p.220) ressaltam a centralidade do indivíduo nos processos de GI e GC (Figura 2), e destacam que a:

[...] gestão da informação desenvolve atividades que propiciam ao indivíduo acessar dados, que estão em bancos, bases, repositórios etc., organizados, tratados e passíveis de recuperação. A partir do acesso aos dados, o indivíduo atribui significado e contexto transformando-os em informação; após avaliar o que é relevante para preencher suas lacunas de conhecimento, se apropria das informações que julga relevantes, as internaliza e as processa por meio de sua condição cognitiva e obviamente dos conhecimentos já existentes; a partir desse processamento, pode ou não gerar novo conhecimento, ou conhecimento incremental. Por último, o indivíduo pode ou não explicitar o novo conhecimento gerado, disseminando-o à sociedade por meio de recursos informacionais. A gestão do conhecimento desenvolve atividades que propiciem ao indivíduo apropriar-se de informações relevantes, bem como externalizá-las a um coletivo. 
Figura 2: Ciclo da GI e GC para gerar 'nova' informação e 'novo' conhecimento.

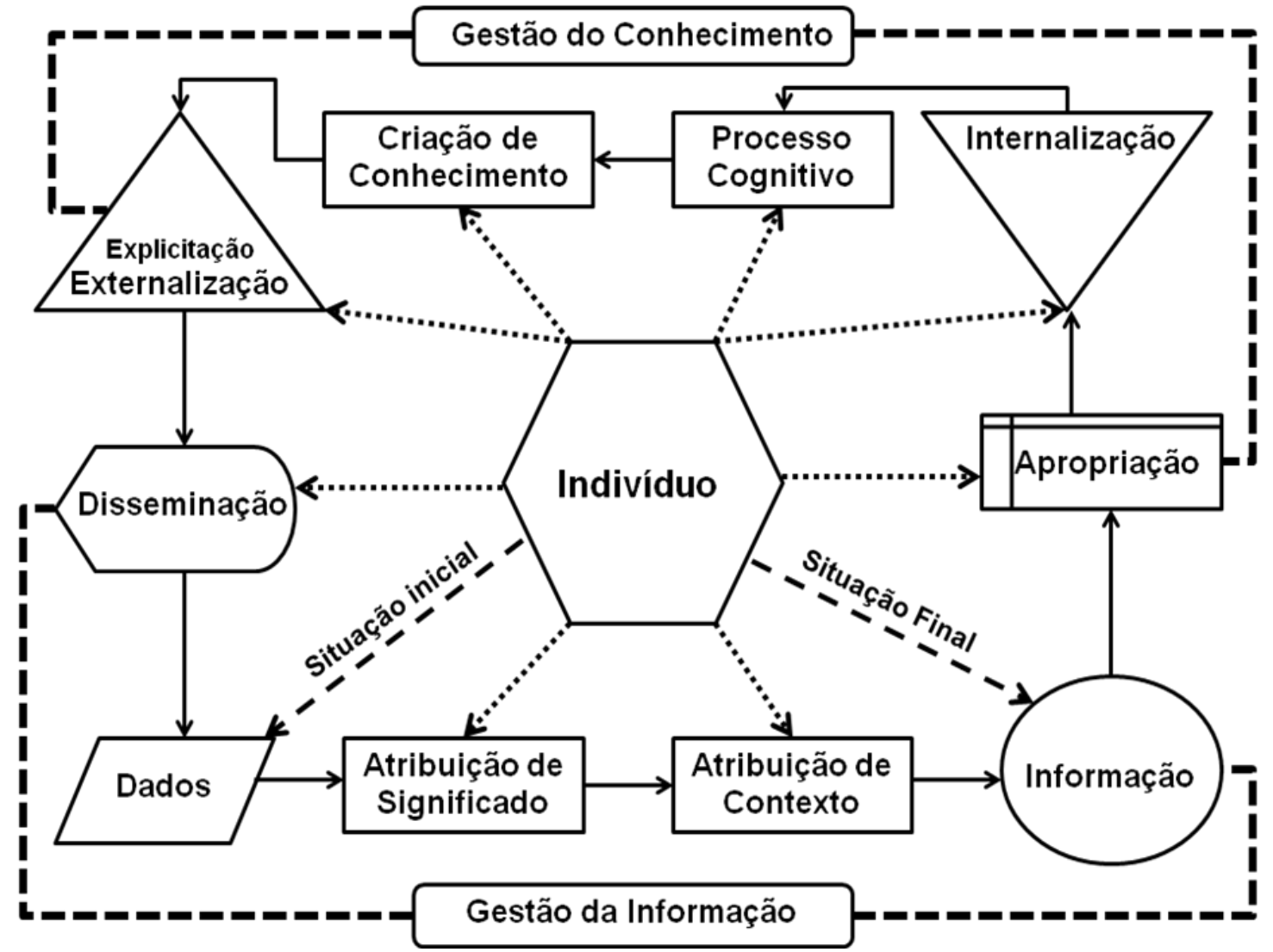

Fonte: Valentim, Jorge e Ceretta-Soria (2014, p.220).

Nessa perspectiva, sendo o sujeito organizacional o elemento central, responsável por realizar e articular todas as atividades necessárias para a geração de informação e conhecimento, necessita ser dotado de competências que o auxilie nesses processos. Doyle $^{3}$ (1992 apud WEBBER; JOHNSTON, 2006, tradução nossa) define que um sujeito é competente em informação quando:

[...] reconhece a necessidade de informação; reconhece que a informação precisa e completa é a base para a tomada de decisão inteligente; identifica as fontes potenciais de informação; desenvolve estratégias de pesquisa bem

3 DOYLE, C. Outcome measures for information literacy within the national education goals of 1990: Final Report of the National Forum on Information Literacy. Washington (DC): US Department of Education, 1992. (ERIC Document, ED 35I033) sucedidas; acessa fontes de informação por meio de tecnologias de informação e de comunicação; avalia as informações; organiza a informação para uma aplicação prática; integra informação nova em um corpo de conhecimento existente; e usa a informação para o pensamento crítico e a resolução de problemas.

Ao se observar o papel do sujeito organizacional nos processos de GI e GC, conjuntamente à definição do que seja um sujeito competente em informação, pode-se considerar a CoInfo fundamental e estratégica para a GI e a GC.

Valentim, Jorge e Ceretta-Soria (2014) sistematizaram e apresentaram uma análise comparativa entre os processos relacionados a CoInfo, a GI e a GC (Quadro 3). 
Quadro 3: Análise comparativa entre as atividades da CoInfo, GI e GC.

\begin{tabular}{|c|c|c|}
\hline COINFO & GI & GC \\
\hline $\begin{array}{l}\text { 1. Capacidade } \\
\text { reconhecer as necessidades } \\
\text { informacionais e formular } \\
\text { questões. }\end{array}$ & $\begin{array}{l}\text { 1. Necessidades de } \\
\text { informação: capacidade de } \\
\text { identificar o que deseja saber, } \\
\text { por que precisa saber, qual é o } \\
\text { enfoque, o que já se sabe, o que } \\
\text { espera descobrir, de que maneira } \\
\text { o resultado pode ajudar. }\end{array}$ & $\begin{array}{l}\text { 1. Obtenha: capacidade } \\
\text { de as pessoas construírem } \\
\text { o conhecimento de que } \\
\text { necessitam. }\end{array}$ \\
\hline $\begin{array}{l}2 . \quad \text { Capacidade } \\
\text { identificar, acessar, } \text { de } \\
\text { pesquiscar, } \\
\text { informação em qualquer mídia. }\end{array}$ & $\begin{array}{l}\text { 2. Aquisição } \\
\text { informação: de } \\
\text { de perceber a extensão e a } \\
\text { diversidade foco da necessidade, } \\
\text { de reconhecer as próprias } \\
\text { limitações cognitivas e de } \\
\text { identificar e monitorar fontes de } \\
\text { informação. }\end{array}$ & $\begin{array}{l}\text { 2. Utilize: capacidade de } \\
\text { as pessoas criarem soluções } \\
\text { inovadoras voltadas aos } \\
\text { clientes. }\end{array}$ \\
\hline $\begin{array}{l}\text { 3. Capacidade } \\
\text { organizar, analisar e avaliar } \\
\text { informação. }\end{array}$ & $\begin{array}{l}3 . \quad \text { Organização e } \\
\text { armazenamento da informação: } \\
\text { capacidade de interagir com os } \\
\text { sistemas organizacionais e de } \\
\text { reconhecer as representações } \\
\text { com que a informação foi } \\
\text { processada. }\end{array}$ & $\begin{array}{l}\text { 3. Aprenda: capacidade } \\
\text { de as pessoas desenvolverem } \\
\text { o próprio capital intelectual } \\
\text { proveniente da aprendizagem } \\
\text { individual. }\end{array}$ \\
\hline $\begin{array}{l}\text { 4. Capacidade de usar } \\
\text { eficazmente informação para } \\
\text { uma aplicação prática e solução } \\
\text { de problemas. }\end{array}$ & $\begin{array}{l}\text { 4. Produtos e serviços } \\
\text { de informação: capacidade de } \\
\text { perceber a qualidade do serviço } \\
\text { e/ou produto informacional } \\
\text { em relação às necessidades } \\
\text { informacionais. }\end{array}$ & $\begin{array}{l}\text { 4. Contribua: capacidade } \\
\text { de as pessoas e as equipes } \\
\text { contribuírem, por meio de ideias } \\
\text { e informações, com base no } \\
\text { conhecimento organizacional. }\end{array}$ \\
\hline \multirow[t]{3}{*}{$\begin{array}{l}\text { 5. Capacidade } \\
\text { apropriar-se informação para } \\
\text { gerar novo conhecimento, } \\
\text { aprende a aprender. }\end{array}$} & 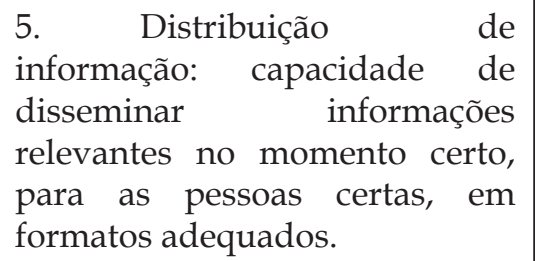 & $\begin{array}{l}\text { 5. Avalie: capacidade de } \\
\text { avaliar o conhecimento gerado } \\
\text { e identificar o que pode ser } \\
\text { melhorado e se está obtendo o } \\
\text { impacto desejado. }\end{array}$ \\
\hline & $\begin{array}{l}6 . \text { Uso de informação: } \\
\text { capacidade de usar informações } \\
\text { para construir conhecimento, } \\
\text { tomar decisões e agir sobre } \\
\text { uma determinada situação } \\
\text { organizacional. }\end{array}$ & $\begin{array}{l}\text { Construa e mantenha: } \\
\text { capacidade de as pessoas } \\
\text { aprimorarem o processo de } \\
\text { construção de conhecimento e } \\
\text { de mantê-lo. }\end{array}$ \\
\hline & $\begin{array}{l}\text { 7. Co m p o r t a m e n to } \\
\text { adaptativo: capacidade } \\
\text { de avaliar, ressignificar e } \\
\text { retroalimentar o processo. }\end{array}$ & $\begin{array}{l}\text { 7. Descarte: capacidade de } \\
\text { as pessoas identificarem o que } \\
\text { de fato é relevante, descartando } \\
\text { o que não possui mais valor. }\end{array}$ \\
\hline
\end{tabular}

Fonte: Valentim, Jorge e Ceretta-Soria (2014, p.222). 
Conforme pode ser observado no Quadro 3, as atividades de CoInfo, GI e GC se inter-relacionam, mesmo que de maneira não estruturada ou previamente planejada, porquanto ao realizar a GI ou GC, o indivíduo realiza atividades relativas a CoInfo automaticamente. Valentim, Jorge e Ceretta-Soria (20014) reforçam essa evidência destacando,

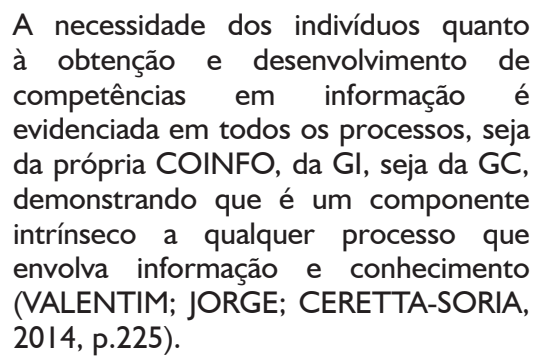

Ao destacarem a centralidade do indivíduo nos processos, bem como as inter-relações com a informação e o conhecimento, torna-se possível evidenciar a necessidade de os sujeitos adquirirem competências em informação em distintos contextos sociais, inclusive em clubes de futebol.

\section{O USO DA INFORMAÇÃO NOS CLUBES DE FUTEBOL: UMA ANÁLISE NO MARÍLIA ATLÉTICO CLUBE (MAC)}

Os clubes de futebol são organizações que possuem como centralidade suas atividades no referido esporte. Lopes e Davis (2006, p.2), afirmam que essas organizações são

\section{[...] geralmente, entidades civis de caráter desportivo, com personalidade jurídica de direito privado, sem fins lucrativos, tendo por objetivo a realização de eventos de caráter social, cultural e desportivo, com a promoção, difusão e aperfeiçoamento da prática da educação física, dos desportos em geral, de reuniões e diversões de caráter desportivo, social, cultural, cívico e recreativo, além de manterem quadros de futebol profissional e de equipes para a prática de desportos amadores.}

Os clubes de futebol são constituídos por uma gama de atividades que, por sua vez, são alimentadas por dados, informações e conhecimento. As atividades podem agrupadas em duas áreas principais: a técnica e a administrativa. A área técnica é responsável por atividades fim direcionadas à prática do futebol, enquanto a área administrativa é responsável por desenvolver atividades meio que subsidiam as atividades técnicas voltadas ao futebol.

O Marília Atlético Clube (MAC) é uma agremiação esportiva, sem fins lucrativos, voltada ao futebol, situada na Cidade de Marília, interior do Estado de São Paulo. Atualmente o clube disputa a Série A-2 do Campeonato Paulista. Sua estrutura organizacional é apresentada na Figura 3.

Figura 3: Estrutura e funções organizacionais do Marília Atlético Clube.

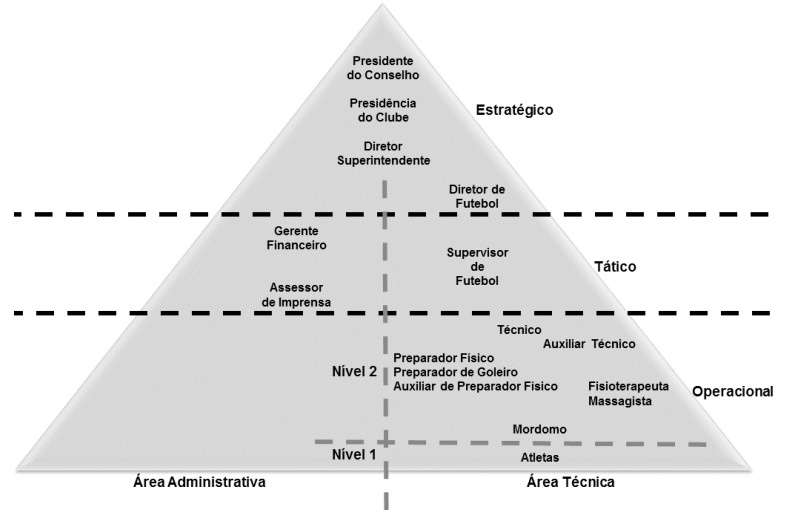

Fonte: Elaboração própria (2016).

Observa-se na Figura 3 que o Clube possui todos os níveis hierárquicos organizacionais, bem como as funções que podem ser agrupadas em grupos, de acordo com o desenvolvimento das atividades técnicas ou administrativas. Dessa maneira, evidencia-se que cada nível organizacional e respectivas funções exercidas pelos sujeitos organizacionais do Clube, geram e usam informações específicas relacionadas às suas atividades, ou seja, cada indivíduo possui sua própria percepção, valorização e aplicação da informação que, por sua vez, está relacionada ao nível e à estrutura em que está inserido (técnica ou administrativa), bem como à função que desempenha no âmbito do Clube.

Observa-se que, em todos os níveis organizacionais torna-se necessário adquirir competência em informação para um melhor aproveitamento e uso das informações. Na base da estrutura organizacional, no nível operacional, 
dividiu-se as atividades em dois níveis, o nível 1, composto pelos atletas e, o nível 2, composto por todos os demais membros que compõe a Comissão Técnica do Clube, que é responsável por proporcionar o suporte necessário aos atletas. Tal divisão ocorre, porquanto cada nível possui um perfil diferente e realiza processos diferentes com os mesmos tipos de informações, o que resulta em diferentes percepções, valorizações e aplicações das informações.

Os atletas, sujeitos organizacionais pertencentes ao nível operacional 1, trabalham com dois principais grupos de informações passados pela Comissão Técnica: informações sobre adversários ou outras informações que proporcionem a eles uma visão prévia das equipes que irão enfrentar e suas possíveis ações a serem realizadas durante as partidas futuras. Normalmente essas informações a priori estão registradas em algum suporte, seja em relatórios, vídeos e demais mecanismos responsáveis por propiciar suporte para registro de tais informações. Um segundo grupo informacional utilizado pelos atletas, refere-se às informações do ambiente geradas em tempo real, isto é, normalmente são informações de jogos e treinamentos que estão sendo vivenciados pelos atletas. Sendo assim, o atleta ao interpretar as informações de uma partida ou de um treinamento, as relaciona com as informações passadas pela Comissão Técnica e realiza suas tomadas de decisões, por meio de suas ações, durante os treinamentos e partidas.

O desenvolvimento da competência em informação nos sujeitos organizacionais é muito peculiar, pois estes devem perceber as informações não registradas em uma determinada situação e relacioná-las com informações passadas a priori, o que exige uma percepção aguçada, rápido processamento e segurança para a tomada de decisão.

Esses mesmos processos ocorrem com os membros da Comissão Técnica, pertencentes ao segundo nível operacional, entretanto, possuem um tempo maior para interpretá-las e processálas para tomarem decisões.

No nível tático, está Supervisor de Futebol, o Gerente Financeiro e o Assessor de Imprensa, esses sujeitos organizacionais são responsáveis por trabalhar com as diretrizes e as informações advindas do nível estratégico e, assim, passam a coordenar a implementação das mesmas no nível operacional.
Evidencia-se que, as competências necessárias para os sujeitos organizacionais do nível tático são bastante diferentes, visto que necessitam transformar as informações diretivas do nível estratégico em informações gerenciais voltadas às atividades organizacionais. Esses indivíduos, cada um em seu contexto de atuação, recebem informações estratégicas, as analisam e as repassam em um formato compreensível tanto para os outros sujeitos do nível tático, quanto para os sujeitos do nível operacional.

O nível estratégico é composto pelo Diretor de Futebol, Diretor Superintendente, Presidência do Clube e Conselheiros representados na Figura 3 pelo Presidente do Conselho. As funções exercidas necessitam de competências em informação num nível mais holístico, possibilitando assim relacionar as informações administrativas e técnicas para uma tomada de decisão mais assertiva.

\section{ANÁLISE DOS DADOS E RESULTADOS DA PESQUISA}

Para a coleta de dados, realizou-se a observação direta no Clube, constatando-se a necessidade de tratar cada nível hierárquico de maneira específica e particularizada. Desse modo, elaborou-se para cada nível hierárquico um instrumento de coleta específico, ajustando-o ao perfil dos sujeitos organizacionais e à complexidade da estrutura organizacional e funções desempenhadas.

Aplicou-se em cada um dos níveis hierárquicos questionários específicos, utilizando-se a Escala de Likert que, de acordo com Gil (1999), baseia-se na Escala de Thurstone, constituída de intervalos. As questões que constituíram os questionários foram agrupadas nas cinco atividades relacionas à CoInfo propostas por Valentim, Jorge e Ceretta-Soria (2014).

$\mathrm{Na}$ base da estrutura do Clube, no nível operacional, estão os sujeitos organizacionais responsáveis pelo core business de um clube de futebol, ou seja, os atletas que estão diretamente relacionados às partidas, campeonatos e torneios. Este nível hierárquico abrange desde os atletas até a Comissão Técnica. Sendo assim, desenvolveu-se dois questionários distintos, o primeiro específico para os atletas, nível 1, e o segundo direcionado à Comissão Técnica, nível 2. 
Tabela 1: Nível operacional - nível 1 - jogadores geral.

\begin{tabular}{|c|c|c|c|c|c|c|c|c|c|c|}
\hline \multirow{2}{*}{ Questões } & \multicolumn{2}{|c|}{ Indiferente } & \multicolumn{2}{|c|}{$\begin{array}{c}\text { Pouco } \\
\text { Importante }\end{array}$} & \multicolumn{2}{|c|}{$\begin{array}{l}\text { Parcial-mente } \\
\text { Importante }\end{array}$} & \multicolumn{2}{|c|}{ Importante } & \multicolumn{2}{|c|}{$\begin{array}{l}\text { Muito } \\
\text { Importante }\end{array}$} \\
\hline & $\mathbf{N}$ & $\%$ & $\mathbf{N}$ & $\%$ & $\mathbf{N}$ & $\%$ & $\mathbf{N}$ & $\%$ & $\mathbf{N}$ & $\%$ \\
\hline \multicolumn{11}{|c|}{ Capacidade de reconhecer as necessidades informacionais e formular questões } \\
\hline $\begin{array}{l}\text { Você acha que a informação é importante } \\
\text { para o desempenho de sua profissão? }\end{array}$ & - & - & 1 & 3,13 & 1 & 3,13 & 11 & 34,37 & 19 & 59,37 \\
\hline $\begin{array}{l}\text { Qual a importância das informações passadas } \\
\text { pelo treinador antes, durante e depois das } \\
\text { partidas? }\end{array}$ & 1 & 3,13 & - & - & 1 & 3,13 & 12 & 37,50 & 18 & 56,24 \\
\hline $\begin{array}{l}\text { Qual a importância do vídeo tape com } \\
\text { partidas dos adversários passadas pela } \\
\text { comissão técnica antes dos jogos? }\end{array}$ & 1 & 3,13 & 1 & 3,13 & 9 & 28,12 & 9 & 28,12 & 12 & 37,50 \\
\hline \multicolumn{11}{|c|}{$\begin{array}{l}\text { Capacidade de identificar, acessar, buscar, pesquisar e localizar informação em qualquer mídia e/ou capacidade de } \\
\text { organizar, analisar e avaliar informaça. }\end{array}$} \\
\hline $\begin{array}{l}\text { Você consegue compreender a informação } \\
\text { que a comissão técnica passa para você antes, } \\
\text { durante e depois das partidas? }\end{array}$ & - & - & - & 1 IIIOA & 1 & 3,13 & 11 & 34,37 & 20 & 62,50 \\
\hline $\begin{array}{l}\text { Como você avalia as informações contidas na } \\
\text { internet (sites, portais, redes sociais, etc.) para } \\
\text { as atividades que você executa? }\end{array}$ & 3 & 9,38 & 9 & 28,12 & 15 & 46,87 & 2 & 6,50 & 3 & 9,38 \\
\hline $\begin{array}{l}\text { Como você avalia as informações contidas } \\
\text { em livros, revistas e jornais para as atividades } \\
\text { que você executa? }\end{array}$ & - & - & 7 & 21,87 & 12 & 37,50 & 11 & 34,37 & 2 & 6,50 \\
\hline $\begin{array}{l}\text { Como você avalia as informações que } \\
\text { possuem origem em empresários e grupos } \\
\text { de investidores para as atividades que você } \\
\text { executa? }\end{array}$ & 1 & 3,13 & 5 & 15,62 & 7 & 21,87 & 14 & 43,75 & 5 & 15,63 \\
\hline \multicolumn{11}{|c|}{$\begin{array}{r}\text { Capacidade de usar eficazmente informação para uma aplicação prática e solução de problemas e/ou capacidade de } \\
\text { apropriar-se informaça para gerar novo conhecimento, aprende a aprender. }\end{array}$} \\
\hline $\begin{array}{l}\text { Qual o impacto das informações no seu } \\
\text { rendimento profissional? }\end{array}$ & 4 & 12,90 & 1 & 3,22 & 5 & 16,13 & 15 & 48,39 & 6 & 19,35 \\
\hline $\begin{array}{l}\text { Caso você possua acesso as informações de } \\
\text { outros departamentos, como você avalia } \\
\text { estas informações em suas atividades? }\end{array}$ & 1 & 3,22 & 2 & 6,44 & 15 & 48,39 & 9 & 29,03 & 4 & 12,99 \\
\hline
\end{tabular}

Fonte: Dados da pesquisa (2013).

A Tabela 1 apresenta os dados coletados e analisados a partir da resposta dos sujeitos que compõe o nível operacional (nível 1), ou seja, os jogadores. Ressalta-se que foram pesquisados todos os atletas profissionais do Clube, totalizando 32 (trinta e dois) sujeitos. É possível observar que, no agrupamento das questões sobre a capacidade de reconhecer as necessidades informacionais e formular questões, apenas 2 (dois) sujeitos $(6,26 \%$ ) não consideraram a informação 'importante' ou 'muito importante' para o seu desempenho profissional. No que tange as informações passadas antes, durante e depois das partidas de futebol, 30 (trinta) sujeitos $(93,74 \%)$, consideram este processo 'importante' ou 'muito importante'. Em relação aos videoteipes passados pela Comissão Técnica antes dos jogos se destaca, pois, 11 (onze) atletas $(34,38 \%)$ consideram essa ação 'indiferente', 'pouco importante' ou 'parcialmente importante', demonstrando que os atletas não consideram o videoteipe um recurso informacional que pode proporcionar uma melhor percepção sobre os pontos fortes e fracos do atleta adversário.

No que tange a capacidade de identificar, acessar, buscar, pesquisar e localizar informação em qualquer mídia e/ou capacidade de organizar, analisar e avaliar informação, observa-se que, em relação ao grau de importância das informações passadas pela Comissão Técnica, apenas 1 (um) (3,31\%) compreende este tipo de informação como 'parcialmente importante', 11 (onze) atletas $(34,37 \%)$ compreendem como 'importante' e 20 (vinte) (62,50\%) como 'muito importante'.

Quanto a avaliação das informações contidas na Internet, revelou-se que tais informações são consideradas 'importantes' ou 'parcialmente importantes' por apenas 5 (cinco) indivíduos (15,88\%), 15 (quinze) $(46,87 \%)$ consideram 'parcialmente importante', 9 (nove) $(28,12 \%)$ classificaram como 'pouco importante' e 3 (três) $(9,38 \%)$ como indiferente. 
As informações contidas em livros, revistas e jornais, 13 (treze) atletas $(40,87 \%)$ as consideram 'importante' ou 'muito importante', enquanto que 12 (doze) sujeitos $(37,50 \%)$ as classificaram 'parcialmente importantes', os outros 7 (sete) $(21,87 \%)$ as avaliaram como 'pouco importantes'. No que tange às informações originárias de empresários e/ou grupos de investidores, 19 (dezenove) indivíduos $(59,38 \%)$ as consideram 'importantes' ou 'muito importantes', 7 (sete) $(21,87 \%)$ as consideram 'parcialmente importantes', 5 (cinco) $(15,62 \%)$ as classificam como 'pouco importante' e apenas 1 (um) atleta $(3,13 \%)$ as compreende de modo 'indiferente'.

Agrupou-se duas questões voltadas à capacidade de usar eficazmente a informação para uma aplicação prática, solução de problemas e/ ou capacidade de apropriar-se da informação para gerar 'novo' conhecimento, 'aprender a aprender'. Avaliou-se primeiramente o impacto das informações para o rendimento profissional dos atletas, 21 (vinte e um) sujeitos $(67,74 \%)$ consideraram as informações 'muito importantes' ou 'importantes', 5 (cinco) (16,13\%) avaliaram essas informações como 'parcialmente importantes', 1 (um) $(3,22 \%)$ como 'pouco importante', enquanto 4 (quatro) sujeitos avaliaram como 'indiferente' $(12,90 \%)$. Questionou-se também o acesso às informações geradas por outros departamentos do Clube, 13 (treze) $(42,02 \%)$ consideram este tipo de informação 'muito importante' ou 'importante', 15 (quinze) atletas $(48,39 \%)$ as classificaram como 'parcialmente importantes', 'pouco importantes' ou 'indiferentes'.

Tabela 2: Nível operacional - nível 2 - comissão técnica.

\begin{tabular}{|c|c|c|c|c|c|c|c|c|c|c|}
\hline \multirow{2}{*}{ Questões } & \multicolumn{2}{|c|}{ Indiferente } & \multicolumn{2}{|c|}{$\begin{array}{c}\text { Pouco } \\
\text { Importante }\end{array}$} & \multicolumn{2}{|c|}{$\begin{array}{l}\text { Parcial-mente } \\
\text { Importante }\end{array}$} & \multicolumn{2}{|c|}{ Importante } & \multicolumn{2}{|c|}{$\begin{array}{l}\text { Muito } \\
\text { Importante }\end{array}$} \\
\hline & $\mathbf{N}$ & $\%$ & $\mathbf{N}$ & $\%$ & $\mathbf{N}$ & $\%$ & $\mathbf{N}$ & $\%$ & $\mathbf{N}$ & $\%$ \\
\hline \multicolumn{11}{|c|}{ Capacidade de reconhecer as necessidades informacionais e formular questões } \\
\hline $\begin{array}{l}\text { Você acha que a informação é importante } \\
\text { para o desempenho de sua profissão? }\end{array}$ & - & - & - & - & - & - & - & - & 7 & 100,00 \\
\hline $\begin{array}{l}\text { Qual a importância do vídeo tape com } \\
\text { partidas dos adversários antes dos jogos? }\end{array}$ & 1 & 12,50 & - & - & - & - & 4 & 50,00 & 3 & 37,50 \\
\hline $\begin{array}{l}\text { Você acha importante que os demais } \\
\text { departamentos repassem informações } \\
\text { importantes para a você? }\end{array}$ & - & - & - & - & - & - & 3 & 37,50 & 5 & 62,50 \\
\hline \multicolumn{11}{|c|}{$\begin{array}{c}\text { Capacidade de identificar, acessar, buscar, pesquisar e localizar informação em qualquer mídia e/ou capacidade de } \\
\text { organizar, analisar e avaliar informaça. }\end{array}$} \\
\hline $\begin{array}{l}\text { Como você avalia as informações contidas na } \\
\text { internet (sites, portais, redes sociais, etc.) para } \\
\text { as atividades que você executa? }\end{array}$ & - & - & - & - & 1 & 14,00 & 3 & 43,00 & 3 & 43,00 \\
\hline $\begin{array}{l}\text { Como você avalia as informações contidas } \\
\text { em livros, revistas e jornais para as atividades } \\
\text { que você executa? }\end{array}$ & - & - & - & - & - & - & 4 & 50,00 & 4 & 50,00 \\
\hline $\begin{array}{l}\text { Como você avalia as informações que } \\
\text { possuem origem em empresários e grupos } \\
\text { de investidores para as atividades que você } \\
\text { executa? }\end{array}$ & - & - & 2 & 25,00 & 1 & 12,50 & 1 & 12,50 & 4 & 50,00 \\
\hline $\begin{array}{l}\text { Caso você possua acesso as informações de } \\
\text { outros departamentos, como você avalia } \\
\text { estas informações? (Caso este processo não } \\
\text { ocorra, não responda) }\end{array}$ & 1 & 20,00 & - & - & - & - & 2 & 40,00 & 2 & 40,00 \\
\hline \multicolumn{11}{|c|}{$\begin{array}{l}\text { Capacidade de usar eficazmente informação para uma aplicação prática e solução de problemas e/ou capacidade de } \\
\text { apropriar-se informaço para gerar novo conhecimento, aprende a aprender. }\end{array}$} \\
\hline $\begin{array}{l}\text { Qual o impacto das informações no seu } \\
\text { rendimento profissional? }\end{array}$ & - & - & - & - & - & - & 3 & 37,50 & 5 & 62,50 \\
\hline $\begin{array}{l}\text { Qual a importância das tecnologias da } \\
\text { informação dentro do seu desempenho } \\
\text { profissional? }\end{array}$ & - & - & - & - & - & - & 4 & 50,00 & 4 & 50,00 \\
\hline $\begin{array}{l}\text { Você consegue compreender e utilizar a } \\
\text { informação antes, durante e depois das } \\
\text { partidas? }\end{array}$ & - & - & - & - & - & - & 2 & 25,00 & 6 & 75,00 \\
\hline $\begin{array}{l}\text { Qual a importância das informações nas } \\
\text { tomadas de decisões, antes, durante e depois } \\
\text { das partidas? }\end{array}$ & - & - & - & - & - & - & - & - & 8 & 100,00 \\
\hline $\begin{array}{l}\text { Você acha importante passar informações } \\
\text { para os demais departamentos? }\end{array}$ & - & - & - & - & 1 & 14,00 & 3 & 43,00 & 3 & 43,00 \\
\hline
\end{tabular}

Fonte: Dados da pesquisa (2013). 
A Tabela 2 congrega os dados dos sujeitos que compõem o nível operacional (nível 2), ou seja, os membros que pertencem a Comissão Técnica. Destaca-se que todos os profissionais que atuam de maneira direta ou indireta apoiando o futebol profissional do Clube foram pesquisados, totalizando 8 (oito) profissionais. Observar-se que, no que tange à capacidade de reconhecer as necessidades informacionais e formular questões, 1 (um) indivíduo não respondeu, sendo assim apenas 7 (sete) apresentaram suas percepções, sendo que todos consideraram esse tipo de informação 'muito importante' para o próprio desempenho profissional. Quanto a importância do videoteipe antes das partidas de futebol, 7 (sete) membros da Comissão Técnica $(87,50 \%)$ consideraram essa atividade 'muito importante' ou 'importante', demonstrando que o uso videoteipe é um recurso informacional relevante, apenas 1 (um) sujeito (12,50\%) considera essa ação 'indiferente'.

Em relação a capacidade de identificar, acessar, buscar, pesquisar e localizar informação em qualquer mídia e/ou capacidade de organizar, analisar e avaliar informação, mais especificamente no que tange ao grau de importância atribuído às informações contidas na Internet, apenas 1 (um) sujeito $(14,00 \%)$ as considera 'parcialmente importante', enquanto que 6 (seis) profissionais $(86,00 \%)$ as consideram 'muito importante' ou 'importante', 1 (um) profissional não respondeu a questão. Quanto as informações contidas em livros, revistas ou jornais todos os profissionais $(100,00 \%)$ as consideram 'muito importantes' ou 'importantes'. As informações originárias de empresários e/ou grupos de investidores, 1 (um) indivíduo não respondeu esta questão, 4 (quatro) sujeitos $(50,00 \%)$ as avaliaram como 'muito importante', 1 (um) (12,50\%) como 'importante', o mesmo percentual como 'parcialmente importante' $(12,50 \%)$, e 2 (dois) profissionais $(25,00 \%)$ as consideram 'pouco importante'. Em relação ao acesso as informações de outros departamentos do Clube, 5 (cinco) profissionais mencionaram que possuem acesso a essas informações, 4 (quatro) indivíduos $(80,00 \%)$ as consideram 'muito importantes' ou 'importantes' e apenas 1 (um) $(20,00 \%)$ as consideram 'indiferentes' para o exercício da atividade profissional.

No que tange a capacidade de usar eficazmente informação para uma aplicação prática, solução de problemas e/ou capacidade de apropriar-se informação para gerar 'novo' conhecimento, 'aprender a aprender', agrupouse cinco questões. Nessa perspectiva, avaliou-se o impacto das informações para o rendimento profissional e todos os profissionais $(100,00 \%)$ consideraram que usar informações é 'muito importante' ou 'importante'. Quanto ao uso da Tecnologia de Informação (TI) para o desempenho profissional, 4 (quatro) profissionais (50,00\%) consideram o uso 'muito importante', sendo que o mesmo percentual de indivíduos considera 'importante'. Em relação ao uso da informação para a tomada de decisão antes, durante e depois das partidas de futebol, 6 (seis) profissionais $(75,00 \%)$ consideraram 'muito importante' e 2 (dois) (25,00\%) consideram 'importante'.

Quanto ao compartilhamento de informações para os demais departamentos do Clube, 6 (seis) profissionais $(86,00 \%)$ consideraram que compartilhar é 'muito importante' ou 'importante', apenas 1 (um) sujeito $(14,00 \%)$ considera esse processo 'parcialmente importante'. 
Tabela 3: Nível tático - gestores e coordenadores.

\begin{tabular}{|c|c|c|c|c|c|c|c|c|c|c|}
\hline \multirow{2}{*}{ Questões } & \multicolumn{2}{|c|}{ Indiferente } & \multicolumn{2}{|c|}{$\begin{array}{c}\text { Pouco } \\
\text { Importante }\end{array}$} & \multicolumn{2}{|c|}{$\begin{array}{l}\text { Parcial-mente } \\
\text { Importante }\end{array}$} & \multicolumn{2}{|c|}{ Importante } & \multicolumn{2}{|c|}{$\begin{array}{l}\text { Muito } \\
\text { Importante }\end{array}$} \\
\hline & $\mathbf{N}$ & $\%$ & $\mathbf{N}$ & $\%$ & $\mathbf{N}$ & $\%$ & $\mathbf{N}$ & $\%$ & $\mathbf{N}$ & $\%$ \\
\hline \multicolumn{11}{|c|}{ Capacidade de reconhecer as necessidades informacionais e formular questões } \\
\hline $\begin{array}{l}\text { Você acha que a informação é importante } \\
\text { para o desempenho de sua profissão? }\end{array}$ & - & - & - & - & - & - & - & - & 3 & 100,00 \\
\hline \multicolumn{11}{|c|}{$\begin{array}{l}\text { Capacidade de identificar, acessar, buscar, pesquisar e localizar informação em qualquer mídia e/ou capacidade de } \\
\text { organizar, analisar e avaliar informaça. }\end{array}$} \\
\hline $\begin{array}{l}\text { Você acha importante que os demais } \\
\text { departamentos repassem informações para } \\
\text { a você? }\end{array}$ & - & - & - & - & - & - & - & - & 3 & 100,00 \\
\hline $\begin{array}{l}\text { Como você avalia as informações contidas na } \\
\text { internet (sites, portais, redes sociais, etc.) para } \\
\text { as atividades que você executa? }\end{array}$ & - & - & - & - & - & - & 2 & 66,67 & 1 & 33,33 \\
\hline $\begin{array}{l}\text { Como você avalia as informações contidas } \\
\text { em livros, revistas e jornais para as atividades } \\
\text { que você executa? }\end{array}$ & - & - & 1 & 33,33 & - & - & 1 & 33,33 & 1 & 33,33 \\
\hline $\begin{array}{l}\text { Como você avalia as informações que } \\
\text { possuem origem em empresários e grupos } \\
\text { de investidores para as atividades que você } \\
\text { executa? }\end{array}$ & - & - & 1 & 33,33 & - & - & 2 & 66,67 & - & - \\
\hline $\begin{array}{l}\text { Caso você possua acesso as informações de } \\
\text { outros departamentos, como você avalia } \\
\text { estas informações em suas atividades? }\end{array}$ & - & - & - & - & - & - & 1 & 33,33 & 2 & 66,67 \\
\hline \multicolumn{11}{|c|}{$\begin{array}{l}\text { Capacidade de usar eficazmente informação para uma aplicação prática e solução de problemas e/ou capacidade de } \\
\text { apropriar-se informaço para gerar novo conhecimento, aprende a aprender. }\end{array}$} \\
\hline $\begin{array}{l}\text { Você consegue compreender e utilizar a } \\
\text { informação em suas atividades no dia a dia? }\end{array}$ & - & - & - & tans & - & - & - & & 3 & 100,00 \\
\hline $\begin{array}{l}\text { Qual a importância das tecnologias da } \\
\text { informação dentro do seu desempenho } \\
\text { profissional? }\end{array}$ & - & - & - & - & - & - & 1 & 33,33 & 2 & 67,67 \\
\hline $\begin{array}{l}\text { Qual o impacto das informações no seu } \\
\text { rendimento profissional? }\end{array}$ & - & - & - & - & - & - & 1 & 33,33 & 2 & 67,67 \\
\hline $\begin{array}{l}\text { Qual a importância das informações } \\
\text { nas tomadas de decisões, nos processos } \\
\text { desempenhados por você? }\end{array}$ & - & - & - & - & - & - & - & - & 3 & 100,00 \\
\hline $\begin{array}{l}\text { Qual a importância das informações } \\
\text { passadas pela diretoria no desempenhar de } \\
\text { suas funções? }\end{array}$ & - & - & - & - & - & - & - & - & 3 & 100,00 \\
\hline
\end{tabular}

Fonte: Dados da pesquisa (2013).

Constatou-se que o desenvolvimento de competências em informação nos 3 três sujeitos organizacionais pertencentes ao nível tático (Tabela 3) é fundamental para a implementação da gestão da informação e do conhecimento no Clube. Em relação a capacidade de reconhecer as necessidades informacionais e formular questões, todos os sujeitos pesquisados avaliam essa capacidade como 'muito importante' para o desempenho profissional.

Quanto à capacidade de identificar, acessar, buscar, pesquisar e localizar informação em qualquer mídia e/ou capacidade de organizar, analisar e avaliar informação, observase que os sujeitos pesquisados consideram essas capacidades 'muito importantes', principalmente em relação às informações de outros departamentos do Clube. No que tange às informações contidas na Internet, apenas 1 (um) profissional $(33,33 \%)$ acredita que este tipo de informação é 'muito importante', 2 (dois) sujeitos (66,67\%) avaliam que essas informações são 'importantes'. Em relação as informações que se apresentam em livros, revistas e jornais, 1 (um) sujeito $(33,33 \%)$ as consideram 'muito importantes', 1 (um) as avaliam como 'importante' (33,33\%), entretanto 1 (um) profissional $(33,33 \%)$ as consideram 'pouco importantes'.

No que tange as informações originárias de empresários e/ou grupos de investidores, 2 (dois) indivíduos $(66,67 \%)$ as consideram 'importantes' 
e 1 (um) indivíduo (33,33\%) as avalia como 'pouco importantes'. Quanto ao acesso as informações geradas por outros departamentos do Clube, 2 (dois) $(66,67)$ profissionais avaliam este tipo de informação como 'muito importante', 1 (um) (33,33\%) avalia como 'importante' para o desenvolvimento de suas atividades.

Quanto à capacidade de usar eficazmente a informação para uma aplicação prática, solução de problemas e/ou capacidade de apropriar-se da informação para gerar 'novo' conhecimento, a aprender a aprender', constatou-se que todos os sujeitos do nível tático $(100,00 \%)$ consideraram que a compreensão e o uso são 'muito importantes' para as atividades desenvolvidas no dia a dia. Quanto ao uso de Tecnologias de Informação e Comunicação (TIC) para o próprio desempenho, 2 (dois) profissionais (66,67\%) consideram o uso 'muito importante' e 1 (um) (33,33\%) destacou que o uso de TIC é 'importante' em suas atividades de rotina.

Sobre o impacto da informação para o próprio rendimento profissional, 1 (um) profissional $(33,33 \%)$ considera a informação 'importante', os demais pesquisados $(66,67 \%)$ a avaliam como 'muito importante'. Todos os sujeitos deste nível organizacional avaliam as informações como 'muito importantes' para a tomada de decisão nos processos que realizam. Obteve-se o mesmo resultado quanto a percepção da importância das informações compartilhadas pela Diretoria do Clube para o desempenho das próprias atividades.

Tabela 4: Nível estratégico - diretoria executiva.

\begin{tabular}{|c|c|c|c|c|c|c|c|c|c|c|}
\hline \multirow{2}{*}{ Questões } & \multicolumn{2}{|c|}{ Indiferente } & \multicolumn{2}{|c|}{$\begin{array}{c}\text { Pouco } \\
\text { Importante }\end{array}$} & \multicolumn{2}{|c|}{$\begin{array}{l}\text { Parcial-mente } \\
\text { Importante }\end{array}$} & \multicolumn{2}{|c|}{ Importante } & \multicolumn{2}{|c|}{$\begin{array}{l}\text { Muito } \\
\text { Importante }\end{array}$} \\
\hline & $\mathbf{N}$ & $\%$ & $\mathbf{N}$ & $\%$ & $\mathbf{N}$ & $\%$ & $\mathbf{N}$ & $\%$ & $\mathbf{N}$ & $\%$ \\
\hline \multicolumn{11}{|c|}{ Capacidade de reconhecer as necessidades informacionais e formular questões } \\
\hline $\begin{array}{l}\text { A Informação é importante para o seu } \\
\text { desempenho profissional? }\end{array}$ & - & - & - & - & - & - & - & - & 4 & 100,00 \\
\hline $\begin{array}{l}\text { O planejamento de longo prazo do Clube } \\
\text { auxilia no desempenho profissional. }\end{array}$ & - & - & - & - & - & - & 1 & 25,00 & 3 & 75,00 \\
\hline \multicolumn{11}{|c|}{$\begin{array}{c}\text { Capacidade de identificar, acessar, buscar, pesquisar e localizar informação em qualquer mídia e/ou capacidade de } \\
\text { organizar, analisar e avaliar informação. }\end{array}$} \\
\hline $\begin{array}{l}\text { Como você avalia o acesso e uso informações } \\
\text { para desempenhar as atividades profissionais } \\
\text { do dia a dia? }\end{array}$ & - & - & - & - & - & - & 1 & 25,00 & 3 & 75,00 \\
\hline $\begin{array}{l}\text { Informações contidas na Internet (sites, } \\
\text { portais, redes sociais, etc.) são importantes } \\
\text { para o desempenho profissional. }\end{array}$ & - & - & 1 & 33,00 & 2 & 67,00 & - & - & - & - \\
\hline $\begin{array}{l}\text { Informações contidas em livros, revistas e } \\
\text { jornais são importantes para o desempenho } \\
\text { profissional. }\end{array}$ & - & - & - & - & 1 & 25,00 & 1 & 25,00 & 2 & 50,00 \\
\hline $\begin{array}{l}\text { Informações geradas por empresários e/ou } \\
\text { grupos de investidores são importantes para } \\
\text { o desempenho profissional. }\end{array}$ & - & - & - & - & 1 & 25,00 & 2 & 50,00 & 1 & 25,00 \\
\hline \multicolumn{11}{|c|}{$\begin{array}{l}\text { Capacidade de usar eficazmente informação para uma aplicação prática e solução de problemas e/ou capacidade de } \\
\text { apropriar-se informaço para gerar novo conhecimento, aprende a aprender. }\end{array}$} \\
\hline $\begin{array}{l}\text { As Informações têm impacto no rendimento } \\
\text { profissional? }\end{array}$ & - & - & - & - & - & - & 1 & 25,00 & 3 & 75,00 \\
\hline $\begin{array}{l}\text { As tecnologias de informação e comunicação } \\
\text { (TIC) são importantes para o desempenho } \\
\text { profissional? }\end{array}$ & - & - & - & - & - & - & 1 & 25,00 & 3 & 75,00 \\
\hline $\begin{array}{l}\text { A Informação é importante para a tomada de } \\
\text { decisão e outros processos desempenhados } \\
\text { no seu dia a dia? }\end{array}$ & - & - & - & - & - & - & 1 & 25,00 & 3 & 75,00 \\
\hline $\begin{array}{l}\text { Informações sobre a estratégia do Clube } \\
\text { são importantes para o seu desempenho } \\
\text { profissional. }\end{array}$ & - & - & 1 & 25,00 & 1 & 25,00 & 2 & 50,00 & - & - \\
\hline $\begin{array}{l}\text { As informações disseminadas pelos níveis } \\
\text { tático e operacional do Clube são importantes } \\
\text { para desempenhar suas funções? }\end{array}$ & - & - & 1 & 25,00 & - & - & - & - & 3 & 75,00 \\
\hline
\end{tabular}

Fonte: Dados da pesquisa (2013). 
A Tabela 4 demonstra o resultado obtido a partir das respostas dos quatro membros que atuam de maneira direta no futebol profissional do Clube. Quanto à capacidade de reconhecer as necessidades informacionais e formular questões, todos os sujeitos $(100,00 \%)$ que essa capacidade é 'muito importante' para o desempenho profissional. Em relação ao planejamento de logo prazo, 3 (três) sujeitos $(75,00 \%)$ o consideram 'muito importante', enquanto 1 (um) profissional o considera 'importante' (25,00\%).

Em relação a capacidade de identificar, acessar, buscar, pesquisar e localizar informação em qualquer mídia e/ou capacidade de organizar, analisar e avaliar informação, mais especificamente no que tange ao acesso e uso da informação para o desempenho das atividades diárias, 3 (três) sujeitos $(75,00 \%)$ consideram 'muito importante', enquanto que 1 (um) profissional $(25,00 \%)$ considera 'importante'. Quanto as informações contidas na Internet, 1 (um) profissional $(33,33 \%)$ as avalia como 'pouco importantes', os demais pesquisados $(66,67 \%)$ as consideram 'parcialmente importantes'.

As informações contidas em livros, revistas e jornais, 1 (um) sujeito $(25,00 \%)$ as considera 'parcialmente importantes', 1 (um) $(25,00 \%)$ as avalia como 'importantes' e os demais 2 (dois) $(50,00 \%)$ as consideram 'muito importantes'. As informações originárias de empresários e/ou grupos de investidores foi considerada 'muito importantes' por 1 (um) indivíduo (25,00\%), 2 (dois) (50,00\%) consideram este tipo de informação 'importante', e 1 (um) $(25,00 \%)$ as avalia como 'parcialmente importante'.

No que tange a capacidade de usar eficazmente a informação para a aplicação prática, solução de problemas e/ou capacidade de apropriar-se da informação para gerar 'novo' conhecimento, 'aprender a aprender', duas questões apresentam os mesmos resultados: sobre o impacto da informação no rendimento profissional e a avaliação das TIC para o desempenho profissional, sendo que consideram 'muito importante' 3 (três) sujeitos $(75,00 \%)$ e 'importante' 1 (um) profissional (25,00\%).

A percepção da informação para desenvolver as atividades do dia a dia e a tomada de decisão foi considerada 'muito importante' para 3 (três) profissionais $(75,00 \%)$, enquanto 1 (um) (25,00\%) a considera 'importante'. Quanto as informações estratégicas do Clube e sua relação com o desempenho profissional, 2 (dois) profissionais $(50,00 \%)$ as consideram 'importantes', 1 (um) $(25,00 \%)$ as percebem como 'parcialmente importantes', enquanto que 1 (um) profissional $(25,00 \%)$ as avalia como 'pouco importantes'. As informações disseminadas pelos outros níveis do Clube são consideradas 'muito importantes' para 3 (três) sujeitos $(75,00)$ e 1 (um) $(25,00 \%)$ as considera 'pouco importantes'.

\section{CONSIDERAÇÕES E REFLEXÕES}

A partir da observação direta e da aplicação dos questionários no Marília Atlético Clube, foi possível obter informações que alinhadas às cinco atividades de CoInfo propostas por Valentim, Jorge e Ceretta-Soria (2014), identificou-se a importância do desenvolvimento de competências em informação nos sujeitos organizacionais do Clube.

A compreensão dos perfis, comportamentos e necessidades informacionais dos sujeitos organizacionais, e a compreensão da dinâmica de cada nível hierárquico, bem como das funções exercidas e das atividades desempenhadas no ambiente do Clube, possibilitou o desenvolvimento de atividades informacionais direcionadas aos sujeitos organizacionais.

Observou-se que quanto mais técnica é a atividade dos sujeitos organizacionais, menor é o tempo para análise das informações, em contrapartida são informações sintéticas que mudam rapidamente a todo instante (Figura 4). As atividades desempenhadas por essas funções exigem pouco tempo para análises e reflexões, influindo no processo decisório, pois normalmente são tomadas de decisões em tempo real.

No outro extremo observou-se que as funções exercidas relacionadas às atividades administrativas, e que se relacionam de modo indireto com a área técnica, trabalham com um grande número de informações analíticas, logo, os sujeitos organizacionais possuem um tempo maior para a análise das informações, pois as mudanças dessas informações ocorrem de maneira mais lenta (Figura 4). As tomadas de decisão realizadas por essas funções impactaram no Clube a médio e longo prazo, tornando-as importantes para a definição de estratégias do Clube. 
Figura 4: Dinâmica informacional no Clube.

- Menor tempo para processar a análise

- Mudança na informação ocorre rapidamente

- Tomada de decisão ocorre em tempo real

- Trabalha com informação pontual e sintética

- Maior tempo para processar a análise

- Mudança na informação ocorre lentamente

- Tomada de decisão ocorre no médio e longo prazo

- Trabalha com muitas informações analíticas

$\checkmark$ Jogadores

$\checkmark$ Comissão

Técnica $\checkmark$ Presidência

$\checkmark$ Diretoria $\checkmark$ Conselheiros

Fonte: Elaboração própria (2016).

Com esse mapeamento é possível desenvolver atividades específicas, seja no âmbito estratégico, seja no âmbito tático e operacional que, proporcionem a aquisição de competências em informação pelos sujeitos organizacionais do Clube, respeitando-se as características e as necessidades informacionais de cada nível e função. Dessa maneira, para a implementação da gestão da informação e da gestão do conhecimento, é essencial primeiramente trabalhar as competências em informação dos sujeitos organizacionais, cujo programa e atividades devem ser desenvolvidas a partir da realidade do Clube.
As estratégias e atividades de CoInfo devem ser realizadas a partir do reconhecimento da estrutura, funções, perfis, comportamentos e atividades realizados pelos sujeitos organizacionais do Clube. Nessa perspectiva, recomenda-se que outras pesquisas que relacionem informação, conhecimento e inteligência sejam realizadas, visando aprofundar a observação e o mapeamento inicial, de maneira a conhecer as particularidades identificadas pela presente pesquisa, no intuito de verificar as características que impactam no uso da informação para a geração de conhecimento no Clube de Futebol.

\section{THE IMPORTANCE OF INFORMATION LITERACY DEVELOPMENT ON SOCCER CLUBS CONTEXT}

ABSTRACT Information is one of the implicit components in different organizational processes, so it is necessary that the organizational individuals are granted the competences to provide the best use of data and information. Observing the environment in which soccer clubs are inserted it is possible to note the use of data and information all the time, and most of the time, being used as a strategic resource. From this perspective, it analyzes the perception, access, sharing and use of data and information aligned with information literacy on the Marilia Athletic Club, of Marilia City, in Sao Paulo State. For this, we used a qualitative research, applying the direct observation method for collecting and analyzing data. From the analysis was possible to notice how organizational individuals use information and highlighted the importance of the information literacy development, so that they can perform their roles, responsibilities and tasks undertaken in the Club. It also evidenced distinct information needs regarding the use of data and information, confirming that the information literacy development on the soccer club's context is essential, after all, everyone involved in the Club have information needs and therefore need to develop skills aimed at better use of information.

Keywords: Information Literacy. Information Management. Sportive Information. Sports Environments. Soccer Clubs. 


\section{REFERENCIAS}

CHOO, C. W. A Organização do conhecimento: como as organizações usam a informação para criar significado, construir conhecimento e tomar decisões. São Paulo: SENAC Editora, 2003. 426p.

DAVENPORT, T.; HARRIS, J. G. Competição analítica. Rio de Janeiro: Campus, 2007.

GIL, A. C. Métodos e técnicas de pesquisa social. 5.ed. São Paulo: Atlas, 1999.

JORGE, C. F. B.; VALENTIM. M. L. P. Informação e esporte: a informação esportiva e sua relação com clubes de futebol. Informação \& Informação, Londrina, v.20, n.1, p.183-208, jun. 2015. Disponível em: <http://www.uel.br/ revistas/uel/index.php/informacao/article/ view/19712>. Acesso em: 21 out. 2015.

LOPES, H. A.; DAVIS, M. D. O ativo jogador de futebol. Revista Pensar Contábil, v.8, n.33, 2006. Disponível em: <http://www.atena.org.br/ revista/ojs-2.2.3-06/index.php/pensarcontabil/ article/view/23>. Acesso em: 4 dez. 2010.
MORAES, C. R. B. de; FADEL, B. Triangulação metodológica para o estudo da gestão da informação e do conhecimento em organizações. In: VALENTIM, M. L. P. (Org.). Gestão da informação e do conhecimento no âmbito da Ciência da Informação. São Paulo: Polis: Cultura Acadêmica, 2008. 272p.; p.27-40.

VALENTIM. M. L. P. Processo de inteligência competitiva organizacional. In: VALENTIM, M. L. P. (Org.). Informação, conhecimento e inteligência organizacional. 2.ed. Marília: FUNDEPE Editora, 2006. 282p; p.9-24.

Inteligência competitiva em organizações: dado, informação e conhecimento. DataGramaZero, Rio de Janeiro, v.3, n.4, ago. 2002. Disponível em: <http://www.dgz.org.br/ ago02/F_I_art.htm>. Acesso em: 15 jan. 2012.

; JORGE, C. F. B.; CERETTA-SORIA, M. G. Contribuição da competência em informação para os processos de gestão da informação e do conhecimento. Em Questão, Porto Alegre, v.20, n.2, p.207-231, dec. 2014. Disponível em: <http:// seer.ufrgs.br/index.php/EmQuestao/article/ view/48642/32122>. Acesso em: 1 out. 2015. 